tuate most excellently the ornithological characters of Yolkshire. The errata, in which there is a curious misprint, is not quite complete, and omits to state that lesser spotted woodpecker should be greater (p. 276), and blue tit should be great tit (p. II4). There are two indices, but unfortunately no map.

The latest work on the birds of Kent (which from its title, indeed, does not claim to be a complete history of the subject) is founded on the naterial brought together in connection with a certain area of that county; but in that limited portion of the county it was noticed that the avifauna would scarcely be of sufficient importance to fill even a small work. It was therefore found advisable to take in the whole of the county. It was also thought desirable to collect all the material hitherto written, and give to those who have done so much towards our knowledge of the birds of Kent full credit for their observations. This has in the main been carried out, and the result has been a compilation giving us a great deal of information about the birds of Kent. Indeed, so anxious have the authors been to give all possible credit to those who have written anything about the local ornithology that they have been mislea into including in their book a number of notes and observations which were not worth reproduction, and the discursiveness of which has made it extremely difficult to arrange the facts in the present work in an orderly and systematic manner. In fact, the book is very well described by its title, and although the reader has never been led to expect a systematic his tory (from a local point of view) of the birds of Kent, the book is a storehouse of facts relating thereto.

We should have been glad to have a complete book on the subject to fill up a blank in the county bird-book shelf; a volume with more personal observations from the authors, and a compilation more complete. The present volume has not been brought up to date. For instance, a valuable paper published in the Zoologist so long ago as February, I907, has been quite overlooked. Had this been consulted the sheldrake might have been added to the lisi of ducks breeding in Kent, while the status in the county of the shoveller and some other ducks, as given in the volume under notice, would have been somewhat modified. Nor has the information relating to the various birds always been brought down even to recent years.

Concerning the guillemot breeding on the Kentish coast, we have a description of the breeding colony in St. Margaret's Bay, written so long ago as $185^{2}$, and a note on the same made in 1887 , but nothing more recent in the way of exact information about the bird breeding on the coast at the present day, although we are told that the bird is, during the summer and breeding season, very numerous. I would surely have been worth the while of one of the authors to ascertain the exact conditions of the breeding place or places after the lapse of twenty years. This is only one instance out of severai. Again, on turning to the articles on the birds more particularly associated with Kent, we find that the greater part of that on the Sandwich tern consists of matter written in the eighteenth century, and we are left in doubt as to whether this bird still breeds annually on the coast or not.

The article on the Kentish plover is more satisfying, although it consists almost entirely of quotations (excellent in themselves), with no qualifications, remarks, or annotations by the authors. An exact statement of the status in Kent of each bird would have been welcome. Kent is credited with a list of 320 species, but of these the black grouse is stated to have long been extinct. We cannot quite follow the authors in NO: 2005 , VOL. 77 ] their application of this word when they go on to say that many of the birds, which might also come under the same word, such as the crane, bustards, cream-coloured courser, \&c., are likely to become occasional visitors, although comparatively extinct in the county (italics ours). There are certainly no grounds for calling the last-named bird " extinct", in the county, as it has never been anything more than a purely accidental straggler to these islands; while the other two species are absolutely, and not only comparatively, extinct as native birds in Great Britain, although they may occur from time to time as visitors. Speaking of the rarer visitors to Kent, the authors remark on one very extraordinary circumstance, viz. that a very large number of the rare seed-eating and other birds should have been found on the Sussex coast, whereas none of them have been observed in the adjoining county of Kent; and the suspicion here expressed that most of these birds have been introduced by human agency has certainly been entertained by many people.

The introduction contains an excellent topographical account of this maritime county (with its 140 miles of coast lapped by tidal water) and its natural features. There is an index, and a map of a handy size and sufficient for its purpose. The frontispiece to this well-got-up volume is a picture from a photograph of a bit of woodland with a woodcock on her nest, and is one of the most beautifully executed and successful pictures of this kind we have ever met with. The difficulty in at first seeing the sitting bird, and the failure of the eye to pick it up at once on again glancing at the picture, as well as the way the figure and details of the bird seem to grow on the sight when once it is located, or located once more, is an admirable representation of the real facts of such cases. The other eight full-page plates depict, birds-like the masked shrike, which has only occurred once in Great Britain-especially associated with Kent, and (especially the one named) are very welcome. But they would have been more useful had they been more correctly coloured. The wing coverts of the lesser kestrel should not have been grey, and the legs of the avocet should have been bluish-grey and not olive-green, a colour which has been also used for the legs of the Kentish plover instead of the correct black or brownish-black. Ornithologists will be glad to have the voluminous literature relating to the birds of Kent collected in this nice-looking volume, the paper, binding, and general get-up of which do the publisher great credit.

\section{MODERN NITRE BEDS}

FVER since the invention of "villainous saltpetre," E the provision of a sufficiency of nitrates has been one of the preoccupations of a ministry of war, and the necessity has become greater rather than less under the conditions of modern warfare. The potassium nitrate that was required for the fabrication of gunpowder is now replaced by the nitric acid used in making the various types of nitro-explosives, but it is always the nitric ion that has to supply the oxygen, and the consumption in a modern battle attains a magnitude of which our immediate predecessors using black powder had no conception. Indeed, one truly scientific argument against war may be drawn from the enormous losses it occasions in the world's limited stock of combined nitrogen.

$\mathrm{Up}$ to the middle of the nineteenth century, India was the only source of nitrates on a large scale, and though a certain amount of nitre was recovered from the efflorescence of the walls of cellars and from artificially made beds of earth mixed with decaying animal 
matter, it was not until the closing of the seas to France during the wars of the Directory that the necessity of an internal supply of nitrates directed the attention of the French savants to the process of nitrification. Their labours reduced to a system the making of nitric beds, but the maximum production was never more than about 5 kilos. of nitre per metre cube after the bed had been established for two years.

It was nearly eighty years later that the researches of Schloesing and Müntz, Warington and Winogradsky showed that nitrification was brought about by bacteria, and at the same time afforded a justification and an explanation of the procedure which had been worked out empirically for the nitre bed. The discovery of the nitrate of soda deposits in Chile left no place for the old nitre beds, but as MM. Müntz and Lainé point out in a very interesting memoir lately presented to the Société d'Encouragement pour l'Industrie nationale ( $T$. cix., pp. $95^{1-1042}$. Paris, I907), the conditions that prevailed at the close of the eighteenth century might recur, and France be again driven to manufacture her war stores of nitrates at home. The authors have therefore been studying in detail the process of nitrification on a large scale to ascertain if the process could be so quickened and intensified as to have any practical value. Starting with sulphate of ammonia as a home product obtainable on a large scale, they worked out the conditions of temperature, concentration, nature of medium, \&c., which would result in the maximum formation of nitrates. The most important step they have made is to show that humus, so far from being inhibitive of nitrification, as most organic substances are, is actually favourable, so that peat or turf, which is almost wholly humus, by reason of its great waterabsorbing powers and the large surface it offers, becomes the best of all substrata for nitrification, if it is also supplied with a sufficiency of carbonate of lime, and a vigorous growth of the necessary organisms is first established in it.

As a final result of their investigations, MM. Müntz and Laine show that the optimum production of nitrates is attained when the ammoniacal liquids percolate through successive beds prepared of finely divided peat mixed with carbonate of lime. It is impossible to begin with a concentrated solution of the sulphate of ammonia, $7 * 5$ grams per litre being about the optimum when the " nitrière" is in full activity; but after this liquid has been nitrified, successive additions of fresh sulphate of ammonia can be made, and the liquid put through another bed until a concentration of 47 grams of calcium nitrate per litre is reached, a figure which is still well below the limit of 20 per cent. at which nitrification ceases. With such an installation the authors expect a daily formation of 7.5 kilos. of nitrate of calcium per metre cube of turf, which represents an extraordinary advance upon the old nitre beds producing 5 kilos. of potassium nitrate per metre cube in two years.

Of course, the process at present is not within the domain of practical politics; ammoniacal nitrogen has practically the same market value as the nitric nitrogen produced, so that the labour expended and the cost of evaporating the final solution would all be wasted; but, as the authors began by pointing out, the occasion may yet arise when a country without command of the sea may require to manufacture its own nitrates. Then " nitrières" could be established by a peat bog to convert into nitrates the ammonia which could be distilled out of the peat. The only doubt that occurs to us is what opening the recent electrical methods of making nitrates from atmospheric nitrogen will even then leave for such a process.

NO. 2005 , VOL. 77]
A. D. $\mathrm{H}$.

\section{PROMINENCE AND CORONAL STRUCTURE. ${ }^{1}$}

$A$ NYONE who has studied the forms of the corona observed at different eclipses knows that these forms change from time to time, going through phases which are more or less repeated every eleven or twelve years according to the solar activity. I have previously indicated (Monthly Notices, R.A.S., vol. 1xiii., No. 8, p. 48I) that there is reason to believe that these changes of shape depend, not on sun-spot action, but on the position and percentage frequency of solar prominences, so that when prominences are most frequent, either near the solar poles or equator, the coronal streamers follow suit.

Prominences can now be observed and photographed every day, but coronal streamers and the lower corona can only as yet be seen during eclipses. From photographs taken during eclipses, it is difficult always to associate certain streamers with prominences, and indeed this should be the case. The reason for this is that prominences are only seen on the limb of the sun that is in profile in such photographs, while streamers may be observed in perspective in addition. The base of a large streamer need not necessarily, therefore, be situated on the solar limb.

It is, I think, now generally acknowledged that a study of eclipse photographs has shown that there is an intimate association ( $a$ ) between streamers and the lower corona, and $(b)$ between the lower corona and prominences. The more, therefore, the form of the lower corona can be attributed to prominence action the more the streamers will depend on prominence activity.

In the eclipses of 1898 , I90I, and I905 " arched" or " envelope" structures were photographed. Thus Prof. Dyson, in describing the series of three arches he photographed in I90I, said, "A very remarkable arch in the corona. Round the prominence three separate arches are shown, one inside the other. . . They have the appearance of cloud over an eruption.",

Again, the Astronomer Royal, referring to his photographs of the 1905 eclipse, writes, "very bright prominence associated with oval rings and arched structure in the corona."

The question arises, are these " arched" forms composed of prominence or coronal material? Photographs taken with prismatic cameras during these eclipses might answer this question, since they are capable of recording, in monochromatic light, images of the sun's surroundings.

An examination of such photographs taken by the Solar Physics Observatory's expedition had, however, shown no indication of any such " arch" systems, but it is quite possible that the comparative faintness of the objects in question and the insufficient lengths of exposure given may account for their absence in the records.

So far as I am aware, no such series of " arches" has been photographed except during the eclipses above mentioned, so that whether the material composing the arches is "coronal" or "prominence" is still undecided.

Although the routine work with the spectroheliograph of the Solar Physics Observatory since the year I904 has been to secure, daily if possible, photographs of the sun's disc and limb in the wavelength of the " $\mathrm{K}$ " line of calcium, it was not until July i 7 of last year that a photograph was obtained which presented a magnificent series of "arches."

1 Abstract of a paper read before the Royal Society on January i6 (Roy. Soc. Proc., Series A, vol. lxxx., No. A 537, pp. 178-r83). 